\title{
Correlation of clinical, cytological and histological findings in oral squamous cell carcinomas
}

\author{
MICHELE CARDOSO SOUSA, MONICA GHISLAINE OLIVEIRA ALVES, \\ LUCIANO ALBINO SOUZA, ADRIANA AIGOTTI HABERBECK BRANDÃO, \\ JANETE DIAS ALMEIDA and LUIZ ANTONIO GUIMARÃES CABRAL \\ Department of Biosciences and Oral Diagnosis, Institute of Science and Technology, UNESP, \\ Univ. Estadual Paulista, São José dos Campos, São Paulo 12245-000, Brazil
}

Received October 7, 2013; Accepted April 24, 2014

DOI: $10.3892 / 01.2014 .2212$

\begin{abstract}
The present study aimed to investigate the efficiency of exfoliative cytology by correlating the clinical lesions of oral squamous cell carcinoma (OSCC) with exfoliative cytology and histopathological findings. Cases of OSCC diagnosed between 1984 and 2010 were analyzed. The inclusion criteria for the present study were the availability of detailed clinical findings and a diagnosis of the disease through exfoliative cytology and histopathology. The cases were assessed and assigned scores, which were then submitted to modal expression analysis, which considers the higher frequency scores, thus relating the variables. The cytological findings demonstrated that the majority of the cases had malignant potential. Exfoliative cytology should be used as a supplementary tool for the diagnosis of OSCC, as it enables the early detection of these lesions. However, cytology should not be used as a substitute for histopathological examination.
\end{abstract}

\section{Introduction}

Oral squamous cell carcinoma (OSCC) is the most common type of cancer of the oral cavity worldwide (1-3). In Brazil, the annual number of cancer-associated mortalities is 6,214 , with $\sim 14,120$ news cases reported in 2010. OSCC is the sixth most common type of cancer and the most frequent type of head and neck cancer (4). The disease primarily affects males between 40 and 65 years old (2). Smoking is the most significant etiological factor for the development of OSCC, and the risk of OSCC increases markedly if smoking is combined with alcohol consumption (5-7). The lateral border of the tongue is the most affected oral site $(2,8)$. In patients

Correspondence to: Mrs. Monica Ghislaine Oliveira Alves, Univ. Estadual Paulista, 777 Engenheiro Francisco José Longo Avenue, São José dos Campos, São Paulo 12245-000, Brazil

E-mail:mgoliveiraalves@gmail.com

Key words: pathology, squamous cell carcinoma, oral cancer, cytology with OSCC, survival is directly associated with early diagnosis $(6,9)$, particularly in those with a potentially malignant disorder, including leukoplakia and erythroplakia, which may precede the development of OSCC or be present in association with OSCC (10).

In the early stages, OSCC frequently clinically manifests as inoffensive with asymptomatic lesions. As a consequence, patients are likely to postpone medical care, thus delaying the diagnosis and adequate treatment, resulting in a poorer prognosis $(11,12)$. By contrast, the difficulty in establishing an accurate diagnosis is lower in cases in which the symptoms are more pronounced (3). Anatomopathological examination of lesion biopsies is the most important method for diagnosing OSCC $(3,13,14)$. However, obtaining a sample through biopsy is invasive and technically difficult (15). Exfoliative cytology has been shown to be an efficient diagnostic method, particularly in the more advanced stages of the disease (13), and cytological analysis is beneficial for assessing cellular alterations in epithelial tissues exhibiting a normal appearance (16).

Raab and Grzybicki (17) proposed that correlation analyses are highly valuable in the fields of cytopathology and surgical pathology, as correlation analysis generates much data that may be used to improve diagnostic testing and screening processes. However, it is necessary to develop standardized methods for correlation analyses and to use correlation data to redesign testing and screening processes to enhance the quality of such processes, as well as patient safety (17).

The present study aimed to correlate the clinical lesions of OSCC with exfoliative cytology and histopathological findings in order to assess the efficiency of exfoliative cytology.

\section{Materials and methods}

Patients. The present study was approved by the Ethics Committee of Institute of Science and Technology, UNESP, Univ. Estadual Paulista (São José dos Campos, Brazil; protocol no. 044/2009-PHCEP) and patients provided written informed consent. Cases of OSCC that were diagnosed at the Institute of Science and Technology, UNESP, Univ. Estadual Paulista between 1984 and 2010 were analyzed. The clinical, histological and cytological records of patients observed at the Stomatology outpatient clinic were reviewed for data collection. 
Table I. Clinical findings according to the degree of the clinical aggressiveness of OSCC.

\begin{tabular}{lccc}
\hline Erythroleukoplakia & $\begin{array}{c}\text { Shallow ulcer or } \\
\text { nodule } \leq 2.5 \mathrm{~cm}\end{array}$ & $\begin{array}{c}\text { Ulcerated or exulcerated } \\
\text { lesion }>2.5 \mathrm{~cm}\end{array}$ & $\begin{array}{c}\text { Destructive ulceroinfiltrative } \\
\text { lesion }\end{array}$ \\
\hline 1 & 2 & 3 & 4 \\
\hline OSCC, oral squamous cell carcinoma. & & \\
\hline
\end{tabular}

Table II. Cytological findings classified according to the criteria proposed by Papanicolaou and Trout (18).

\begin{tabular}{lccc}
\hline Class I and II & Class III & Class IV & Class V \\
\hline 1 & 2 & 3 & 4 \\
\hline
\end{tabular}

Class I normal; class II, inflammatory changes; class III, atypical cells, suspect smear; class IV, non-conclusive of malignancy; and class V, malignant.

Patients were included in the present study based on the following inclusion criteria: (i) The availability of detailed clinical findings; and (ii) the diagnosis of OSCC using exfoliative cytology and histopathology. Scores were attributed to the morphological features of each case. The clinical findings are presented based on the degree of aggressiveness of the OSCC (Table I).

Exfoliative cytology. Patients underwent exfoliative cytology of the lesion using a cytobrush (Vagispec, Jaraguá do Sul, SC, Brazil), and all samples were stained using the Papanicolaou method. The results were classified with using the following criteria proposed by Papanicolaou and Trout (18) (Table II): Class I, normal; class II, inflammatory changes; class III, atypical cells, suspect smear; class IV, non-conclusive of malignancy; and class $\mathrm{V}$, malignant.

Histological staining. The histological sections obtained from the patients with OSCC were stained using hematoxylin and eosin, and were analyzed using light microscopy by an examiner. Slides were scored between 1 and 4 according to the system proposed by Anneroth et al (19) (Table III).

For better correlation, the results were submitted to modal expression using the scores, considering the higher frequency scores related to each other.

\section{Results and Discussion}

In total, 53 of the 316 OSCC cases met the inclusion criteria; 41 were male and 12 were female, with an age range between 28 and 88 years. Table IV shows the correlation between the clinical, cytological and histological findings. Among the 53 cases analyzed, $28.3 \%$ were classified as Papanicolaou class III, $3.77 \%$ as class IV and $58.71 \%$ as class V. Thus, $86.79 \%$ of the cases were found to have malignant potential.

Previous studies that have compared the efficacy of exfoliative cytology and histopathology for the diagnosis of OSCC have shown that exfoliative cytology is an effective method $(1,13,20)$. In the present study, only 53 cases of OSCC met the inclusion criteria. The majority of these cases were from the Stomatology Outpatient Clinic of the Institute of Science and Technology, indicating that exfoliative cytology may be primarily used at universities. Although this technique is practical, inexpensive, simple and non-invasive $(3,13,21)$, dentists do not use this method routinely for the early detection of $\operatorname{OSCC}(14,22)$.

The results of the present study showed no direct correlation between the clinical, cytological and histological scores. This finding indicates that it is not possible to predict the behavior of OSCC based solely on the observation of clinical features. In accordance with this, in the present study, a histological score of 2 or 3 was attributed to three cases of erythroleukoplakia, demonstrating that the mild clinical findings did not correspond with the aggressive histological characteristics. In addition, a histological score of 1 was attributed to one case presenting a nodule that was clinically scored as 2 .

In the present study, three cases showing clinical features of a shallow ulcer $<2 \mathrm{~cm}$, exulceration $>2.5 \mathrm{~cm}$ and a destructive and infiltrative ulcer were classified as Papanicolaou class I or II using cytological analysis. These findings, which demonstrate the lack of efficiency of exfoliative cytology, may be explained by non-representative sampling and/or individual subjectivity $(17,23)$, since this is a retrospective study in which the cytological tests were not performed by the same examiner.

Exfoliative cytology involves the analysis of superficial epithelial cells that are obtained through scraping $(24,25)$ the lesion using a sterile cytobrush (22). Thus, collecting deeper cells from plaques or nodules is difficult, which compromises the accuracy of the technique $(1,15)$. This limitation was observed in the present study, in which three cases presenting with nodules and one case presenting with an erythroleukoplakia plaque were diagnosed as cytological score 1 . In the present study, analysis of the cytological findings suggested that the majority of the cases had malignant potential, indicating that exfoliative cytology may be beneficial as a supplementary tool for diagnosing OSCC.

Oral cytology is useful for monitoring patients undergoing treatment in order to guide the selection of sites for incisional 

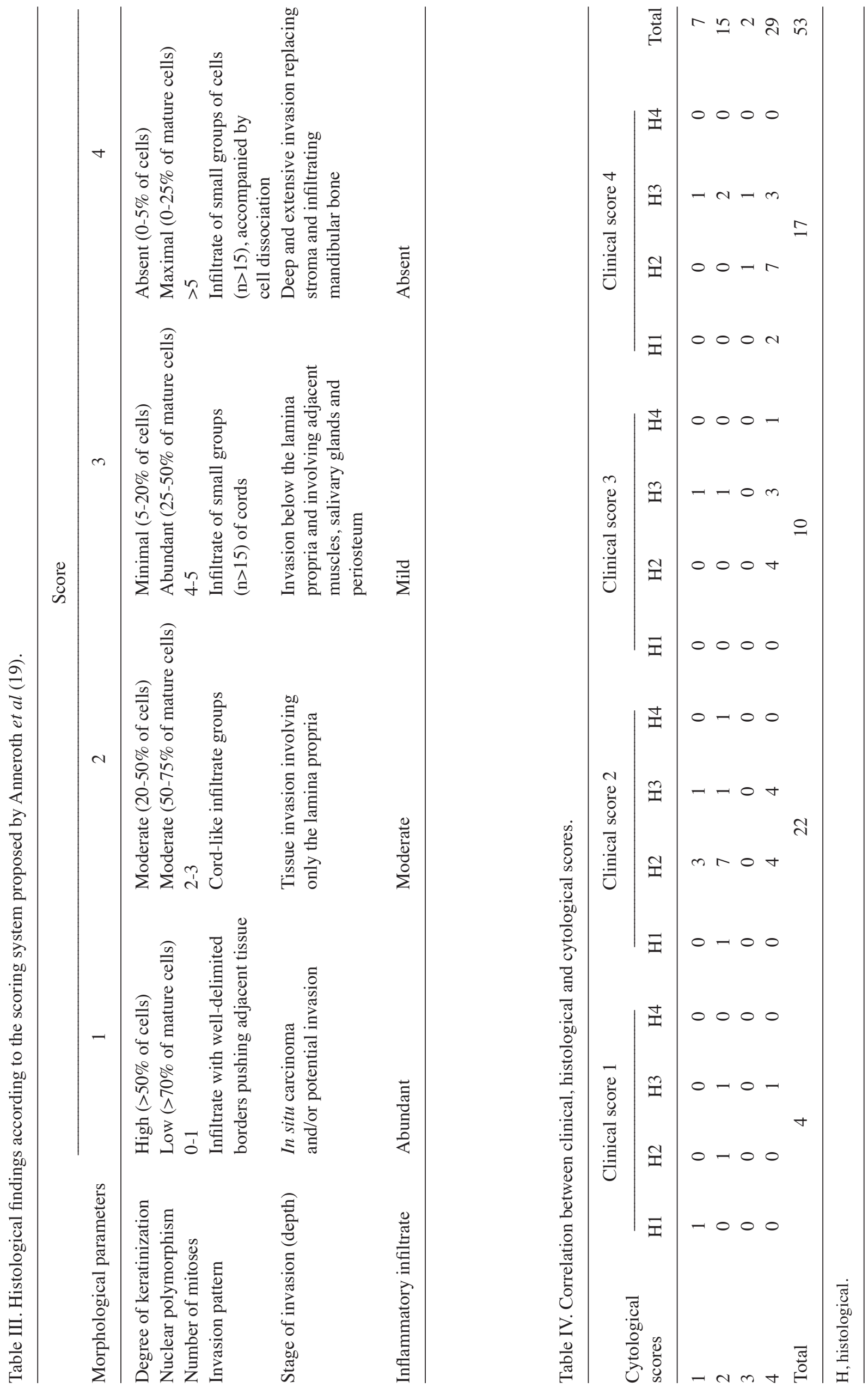
biopsies $(26,27)$ and to analyze lesions with malignant potential with high sensitivity and specificity, leading to an early diagnosis (28). In addition, oral cytology has been used to identify changes prior to their clinical visibility (27). The advantages of exfoliative cytology make it a particularly useful diagnostic method for obtaining early test results. Furthermore, cases with more symptoms that are associated with more advanced stages of the disease are easily diagnosed due to the obvious clinical features (29).

At present, dentists observe the development of non-specific ulcers for 14 days after the first visit, and then establish an objective diagnosis (30). Thus, exfoliative cytology may obtain a more rapid diagnosis $(5,19,31)$.

Although exfoliative cytology should not be used as a substitute for histopathological examination, the present study has demonstrated the efficiency of exfoliative cytology for the diagnosis of OSCC and has shown that it may be beneficial as an additional tool to enable early referral of patients to a specialized service.

\section{References}

1. Ramaesh T, Mendis BR, Ratnatunga N and Thattil RO: Diagnosis of oral premalignant and malignant lesions using cytomorphometry. Odontostomatol Trop 22: 23-28, 1999.

2. de Faria PR, Cardoso SV, de A Nishioka S, Silva SJ, Loyola AM: Clinical presentation of patients with oral squamous cell carcinoma when first seen by dentists or physicians in a teaching hospital in Brazil. Clin Oral Invest 7: 46-51, 2003.

3. Driemel O, Kunkel M, Hullmann M, von Eggeling F, Müller-Richter U, Kosmehl H and Reichert TE: Diagnosis of oral squamous cell carcinoma and its precursor lesions. J Dtsch Dermatol Ges 5: 1095-1100, 2007 (In German).

4. Jemal A, Siegel R, Ward E, Hao Y, Xu J, Murray T and Thun MJ: Cancer Statistics, 2008. CA Cancer J Clin 58: 71-96, 2008.

5. Ahmed HG, Ebnoof SO, Hussein MO and Gbreel AY: Oral epithelial atypical changes in apparently healthy oral mucosa exposed to smoking, alcohol, peppers and hot meals, using the AgNOR and Papanicolaou staining techniques. Diagn Cytopathol 38: 489-495, 2010.

6. Jan JC, Hsu WH, Liu SA, Wong YK, Poon CK, Jiang RS, Jan JS and Chen IF: Prognostic factors in patients with buccal squamous cell carcinoma: 10-year experience. J Oral Maxillofac Surg 69: 396-404, 2011.

7. Zygogianni AG, Kyrgias G, Karakitsos P, Psyrri A, Kouvaris J, Kelekis N and Kouloulias V: Oral squamous cell cancer: early detection and the role of alcohol and smoking. Head Neck Oncol 3: 2, 2011.

8. Holmes JD, Martin RA and Gutta R: Characteristics of head and neck cancer patients referred to an oral and maxillofacial surgeon in the United States for management. J Oral Maxillofac Surg 68: 555-561, 2010.

9. Bachar G, Hod R, Goldstein DP, Irish JC, Gullane PJ, Brown D, Gilbert RW, Hadar T, Feinmesser R and Shpitzer T: Outcome of oral tongue squamous cell carcinoma in patients with and without known risk factors. Oral Oncol 47: 45-50, 2011.

10. Liu W, Wang YF, Zhou HW, Shi P, Zhou ZT and Tang GY: Malignant transformation of oral leukoplakia: a retrospective cohort study of 218 Chinese patients. BMC Cancer 10: 685, 2010.

11. Pitiphat W, Diehl SR, Laskaris G, Cartsos V, Douglass CW and Zavras AI: Factors associated with delay in the diagnosis of oral cancer. J Dent Res 81: 192-197, 2002.
12. Peacock ZS, Pogrel MA and Schmidt BL: Exploring the reasons for delay in treatment of oral cancer. J Am Dent Assoc 139: 1346-1352, 2008.

13. Maraki D, Becker J and Boecking A: Cytologic and DNA-cytometric very early diagnosis of oral cancer. J Oral Pathol Med 33: 398-404, 2004.

14. Morse DE, Psoter WJ, Cuadrado L, Jean YA, Phelan J, Mittal K, Buxó CJ, Cruz GD and Elias A: A deficit in biopsying potentially premalignant oral lesions in Puerto Rico. Cancer Detect Prev 32: 424-430, 2009.

15. Epstein JB, Zhang L and Rosin M: Advances in the diagnosis of oral premalignant and malignant lesions. J Can Dent Assoc 68: 617-621, 2002.

16. Burzlaff JB, Bohrer PL, Paiva RL, Visioli F, Sant'Ana Filho M, da Silva VD and Rados PV: Exposure to alcohol or tobacco affects the pattern of maturation in oral mucosal cells: a cytohistological study. Cytopathology 18: 367-375, 2007.

17. Raab SS and Grzybicki DM: Cytologic-histologic correlation. Cancer Cytopathol 119: 293-309, 2011.

18. Papanicolaou GN and Traut HF: Diagnosis of uterine cancer by the vaginal smear. Am J Med Sci 206: 811, 1943.

19. Anneroth G, Batsakis J and Luna M: Review of literature and a recommended system of malignancy grading in oral squamous cell carcinomas. Scand J Dent Res 95: 229-249, 1987.

20. Divani S, Exarhou M, Theodorou LN, Georgantzis D and Skoulakis H: Advantages and difficulties of brush cytology in the identification of early oral cancer. Arch of Oncol 17: 11-12, 2009.

21. Mehrotra R, Gupta A, Singh M and Ibrahim R: Application of cytology and molecular biology in diagnosing premalignant or malignant oral lesions. Mol Cancer 5: 11, 2006.

22. Queiroz JB, Lima CF, Burim RA, Brandao AA, Cabral LA and Almeida JD: Exfoliative cytology of the oral mucosa: comparison of two collection methods. Gen Dent 58: e196- e199, 2010.

23. Nichols ML, Quinn FB Jr, Schnadig VJ, Zaharopoulos P, Hokanson JA, Des Jardins L and McCracken MM: Interobserver variability in the interpretation of brush cytologic studies from head and neck lesions. Arch Otolaryngol Head Neck Surg 117: 1350-1355, 1991

24. Almeida JD, Cabral LAG and Brandão AAH: Exfoliative cytology as a diagnostic method in stomatology. J Dent Res 73: 765,1994

25. Acha A, Ruesga MT, Rodríguez MJ, Martínez de Pancorbo MA and Aguirre JM: Applications of the oral scraped (exfoliative) cytology in oral cancer and precancer. Med Oral Patol Oral Cir Bucal 10: 95-102, 2005 (In Spanish).

26. Potter TJ, Summerlin DJ and Campbell JH: Oral malignancies associated with negative transepithelial brush biopsy. J Oral Maxillofac Surg 61: 674-677, 2003.

27. Pérez-Sayánsm M, Somoza-Martín JM, Barros-Angueira F, Reboiras-López MD, Gándara-Vila P, Gándara Rey JM and García-García A: Exfoliative cytology for diagnosing oral cancer. Biotech Histochem 85: 177-187, 2010.

28. Pérez-Sayáns M,Reboiras-López MD, Gayoso-Diz P, Seijas-Naya F, Antúnez-López JR, Gándara-Rey JM and García-García A: Non-computer-assisted liquid-based cytology for diagnosis of oral squamous cell carcinoma. Biotech Histochem 87: 59-65, 2012.

29. Friedrich RE: Delay in diagnosis and referral patterns of 646 patients with oral and maxillofacial cancer: a report from a single institution in Hamburg, Germany. Anticancer Res 30: 1833-1836, 2010

30. Epstein JB, Gorsky M, Fischer D, Gupta A, Epstein M and Elad S: A survey of the current approaches to diagnosis and management of oral premalignant lesions. J Am Dent Assoc 138: 1555-1562, 2007.

31. Mishra M,Mohanty J,Sengupta S and Tripathy S: Epidemiological and clinicopathological study of oral leukoplakia. Indian J Dermatol Venereol Leprol 71: 161-165, 2005. 